\title{
Arte conceptual (neoliberal) en El Otro Sendero
}

\author{
Mijail Mitrovic Pease \\ Pontificia Universidad Católica del Perú \\ mijailmitrovicpease@gmail.com
}

\begin{abstract}
Resumen
El presente artículo analiza el dossier fotográfico del libro El Otro Sendero (Lima, 1986) del economista peruano Hernando De Soto, a través de ciertos debates sobre el arte conceptual y la crítica institucional en el arte contemporáneo global. El autor busca realizar una crítica de la ideología neoliberal en el Perú, tomando como caso de análisis su autor y libro más representativo.
\end{abstract}

Palabras clave: crítica institucional, neoliberalismo, ideología, cultura visual, desborde popular

\begin{abstract}
By means of certain debates on conceptual art and institutional critique in global contemporary art, this article analyses the photographic dossier in Hernando De Soto's El Otro Sendero (Lima, 1986). The dossier operates as an art object that stands for a new neoliberal vision of contemporary Peru.
\end{abstract}

Keywords: Institutional critique, neoliberalism, ideology, visual culture

Después de la crisis del 2008 las críticas al neoliberalismo proliferan en todo el mundo, denunciándolo como un modelo que encarna la desigualdad, la explotación, el desastre medioambiental y la polarización de las sociedades entre un $99 \%$ precarizado y un $1 \%$ cada vez más poderoso. Pese a ello, desde la Constitución Política de 1993 en el Perú se ha establecido firmemente un arreglo entre las élites económicas y el Estado que descansa sobre las premisas generales de dicha ideología ${ }^{1}$. No se trata, sin embargo, de la aplicación de un recetario extranjero, pues el neoliberalismo empezó su tradición local a través del pensamiento del economista Hernando De Soto, quien publicara en 1986 El Otro Sendero ${ }^{2}$. En

1 En una muy general definición del neoliberalismo, David Harvey sostiene que “...es, ante todo, una teoría de prácticas político-económicas que afirma que la mejor manera de promover el bienestar del ser humano consiste en no restringir el libre desarrollo de las capacidades y de las libertades empresariales del individuo dentro de un marco institucional caracterizado por derechos de propiedad privada fuertes, mercados libres y libertad de comercio" (Harvey, 2007: 6).

2 Para un perfil del economista, ver Adrianzén (2014a). Es necesario anotar que autores como Enrique Ghersi recusan la categoría "neoliberal”, pues la consideran “....una figura retórica por la cual se busca pervertir el sentido original del concepto [el liberalismo] y asimilar nuestras ideas a otras ajenas, con el propósito de desacreditarlas en el mercado político" (2004: 294). 
colaboración con Enrique Ghersi y Mario Ghibellini, junto al trabajo colectivo del Instituto Libertad y Democracia (ILD) -el think tank fundado por él mismo en 1981-, De Soto propuso una interpretación de la realidad nacional que subvirtió los aparatos conceptuales que las ciencias sociales, desde la izquierda, empleaban para comprender el país. Desarrollaré en lo que sigue un argumento acaso imprevisto: además de proponer una nueva lectura del Perú desde la economía política neoliberal, en dicho libro aparecen ciertas operaciones artísticas que articulan visual y conceptualmente su propuesta ideológica ${ }^{3}$.

\section{La apuesta política de De Soto}

Para De Soto, el llamado desborde popular, producto de las migraciones internas a la capital, constituía una oportunidad para reconceptualizar al sujeto popular urbano, alejándose de la imagen de un transgresor del orden legal y haciéndolo aparecer como un capitalista espontáneo que, por sí mismo, se descubrió como la verdadera fuerza motriz del país. En la teoría y en la práctica, el principal enemigo del informal no sería otro informal, sino el "Estado mercantilista", al que habría que reducir desde dentro para promover el despliegue de la libre competencia en el mercado ${ }^{4}$. En este contexto, la guerra popular senderista socavaba el deseo capitalista de los informales, por lo que bautizaron su vía como el otro sendero ${ }^{5}$. Siguiendo a Adrianzén, De Soto propuso un giro radical sobre cómo se entendían las clases populares e informales, haciéndolas aparecer como “...agentes sociales altamente competitivos e innovadores (...) dejan[do] de ser considerados como un problema social para convertirse en el centro de la solución de un nuevo programa de desarrollo del país" (2010:96). La retórica del autor presenta la informalidad como un dato de realidad, de manera que la solución a los problemas del país será encontrada si logramos captar espontáneamente el significado de este fenómeno social (De Soto, 1986:XXXII).

En la misma década la izquierda produciría múltiples enfoques sobre las masas populares, aspirando a traducirse en estrategias para su articulación política: la "historia desde abajo" (López, 2009), la antropología de la migración (Degregori, Blondet y Lynch, 1986) y el discurso culturalista (Matos Mar, 1984) -entre otros- compartieron más de lo deseado con la propuesta desotiana ${ }^{6}$. Para José Matos Mar, por ejemplo, el "poder creativo del hombre peruano" -característica cuasi milenaria de la sociedad andina, que los migrantes cargaban consigo- debía ser canalizado políticamente hacia un orden social más democrático. Matos Mar pensaba dentro del horizonte socialista en una década donde las bases epistemológicas y políticas de la izquierda peruana entrarían en crisis, como resultado del declive de los movimientos populares bajo la guerra entre Sendero Luminoso y el Estado (Gonzáles, 2011:36). Para el discurso desotiano, por el contrario,

3 Me interesa examinar el libro desde una perspectiva análoga a la desplegada por Luis Camnitzer (2009) en su búsqueda de los orígenes del conceptualismo en América Latina, donde analiza la producción de figuras tan dispares como Simón Rodríguez, los Tupamaros y el canon de conceptualistas de la región.

4 Es elocuente el discurso de Mario Vargas Llosa en el prólogo a la primera edición del libro: "Un Estado grande no es un sinónimo de fuerte, sino, en la mayoría de los casos, de lo opuesto. Esos inmensos entes que en nuestros países drenan las energías productivas de la sociedad para alimentar su estéril existencia, son, en verdad, colosos con pies de arcilla. Su propio gigantismo los vuelve torpes e ineptos y su ineficiencia e inmoralidad los priva de todo respeto y autoridad, sin los cuales ninguna institución u organismo puede funcionar cabalmente" (De Soto, 1986: XXVIII).

5 Sobre esto, De Soto comenta lo siguiente: "Nadie ha pensado que la mayoría de los peruanos pobres se adelantó a los revolucionarios y está cambiando las estructuras del país y que lo que les corresponde a los políticos es, más bien, ordenar el cambio, darle el marco institucional adecuado para que pueda ser aprovechado y gobernado" (1986: 293). Nótese que el argumento del 'marco institucional' bien podría haber sido suscrito por enfoques como el de Matos Mar, pero el ambiguo significado del término permite a De Soto entrar en diálogo con posturas que, en principio, no suscribirían la tesis neoliberal de la reducción del Estado a su mínima expresión.

6 El vínculo entre las propuestas de Matos Mar y De Soto ha sido señalado por Francisco Durand (2007), argumentando que ambos autores sostenían cierta esperanza en que el sector informal podría ser integrado a la sociedad "oficial", aunque planteando vías antagónicas para conseguir aquel objetivo. 
esas potencias culturales y colectivas debían ser entendidas como energías puramente individuales, listas para ser liberadas a través de las fuerzas del mercado.

Guillermo Rochabrún sostiene que el éxito de aquella propuesta consiste en haber otorgado legitimidad al sector informal "a través de mecanismos exclusivamente semánticos: creando nuevos significados” (2007:306-307) donde los individuos identificarán al Estado, de allí en más, como el responsable de su miseria. A diferencia del discurso de buena parte de la izquierda, quienes se deslizaron hacia identificaciones prematuras entre lo popular y lo democrático, el neoliberalismo local nos muestra a lo popular como una posición estructural: estar en contra de su "real enemigo" -el Estado- y no como una configuración cultural producto de las migraciones ${ }^{7}$. Esta perspectiva se diferencia aún hoy de aquellas concepciones idealizadas de lo popular que no reparan en su carácter ambiguo y contradictorio. Veamos el siguiente pasaje:

El beneficio que esta nueva clase empresarial [los informales] representa para el Perú es mucho más significativo que los perjuicios que le ocasionan terroristas y mercantilistas. La inmensa mayoría de la población comparte una actitud, un deseo de vencer la pobreza y tener éxito (De Soto, 1986:297).

Así, el mérito mayor de De Soto consiste, con Rochabrún una vez más, en proponer que la pregunta por lo popular no obtendrá respuesta alguna si se formula en términos de qué es -sus supuestos rasgos intrínsecos- sino "en razón de lo que cada uno hace y/o está en posibilidad de hacer" (2007:308). Un discurso práctico donde todos, si el Estado no lo impide, podremos hacernos empresarios ${ }^{8}$. En resumen, el "viejo" problema -los informales- queda habilitado como un nuevo sujeto político, mientras que se establece un nuevo problema y enemigo, a saber, el Estado ${ }^{9}$.

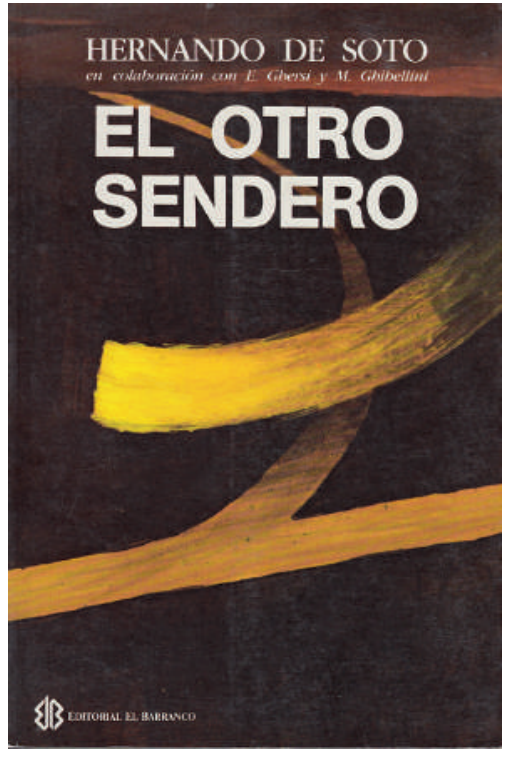

Fig.1. Hernando De Soto (en colaboración con Enrique Ghersi, Mario Ghibellini y el Instituto Libertad y Democracia), El Otro Sendero. La Revolución Informal, portada de la primera edición [Fotografía del autor].

7 Es interesante que De Soto haya sugerido reemplazar la palabra "liberal" por "popular" en el texto, mostrando así las distancias conceptuales frente al discurso de la izquierda. Como comenta Ghersi: "Recién habíamos terminado El Otro Sendero, cuando [De Soto] me pidió que eliminara completamente del texto la palabra liberal -que por supuesto estaba por todas partes- y que la reemplazara por la palabra popular. Así, la economía liberal vino a convertirse en la economía popular; la sociedad liberal, en la sociedad popular; la filosofía liberal, en la popular. Su explicación fue que en esos momentos no era compatible con el buen mercadeo apelar al término, ya que podría generar innecesariamente resistencias. Aunque no estuve de acuerdo, recuerdo que De Soto, que se presume de gran vendedor, terminó imponiéndose” (2004:306).

8 Todos podremos reconocernos en dicha identidad social. Dice Adrianzén: "De Soto descarta la dicotomización hegemónica del espacio social entre explotadores y explotados, para proponer una nueva frontera en torno a la ley [el Estado] y a la exclusión/inclusión de los nuevos actores respecto a ella. Proletarios y burgueses, o si se quiere trabajadores y empresarios, dejan de ser, para De Soto, actores necesariamente antagónicos, para convertirse en aliados que combaten codo a codo por ingresar a la campana de cristal de la legalidad" (2010:102).

9 Este marco ideológico tendrá consecuencias más amplias para la sociabilidad local: para el sociólogo Danilo Martuccelli, Lima es actualmente una ciudad donde las relaciones sociales se estructuran a través de una matriz informal, producto de la conversión de la informalidad en un proyecto político por parte de intelectuales como De Soto. La informalidad, como representación social y política arraigada en los sectores populares -pero que atraviesa hoy a todas las clases sociales-, no es únicamente un destino inexorable de la condición migrante, sino una imagen arquetípica de nuestra sociedad (2015:113). 


\section{Arte conceptual y crítica institucional neoliberal}

En sus primeras ediciones el libro es un objeto artístico por derecho propio (fig.1). Notemos que la carátula presenta una pintura de Fernando De Szyszlo -obsequiada al autor-, mientras que el prólogo lo hace nada menos que Mario Vargas Llosa ${ }^{10}$. Alberto Flores Galindo supo leer en la objetualidad del libro una coalición tramposa: las artes y las letras "cultas", clamando a diestra y siniestra su carácter desinteresado y autónomo, cruzaban esfuerzos para acompañar estéticamente la apuesta política de De Soto ${ }^{11}$. Aunque a primera vista encontremos aspectos estéticos relevantes para el análisis, será "La informalidad en fotos", el dossier de imágenes que divide a la mitad el libro, el que pasaré a comentar en adelante ${ }^{12}$.

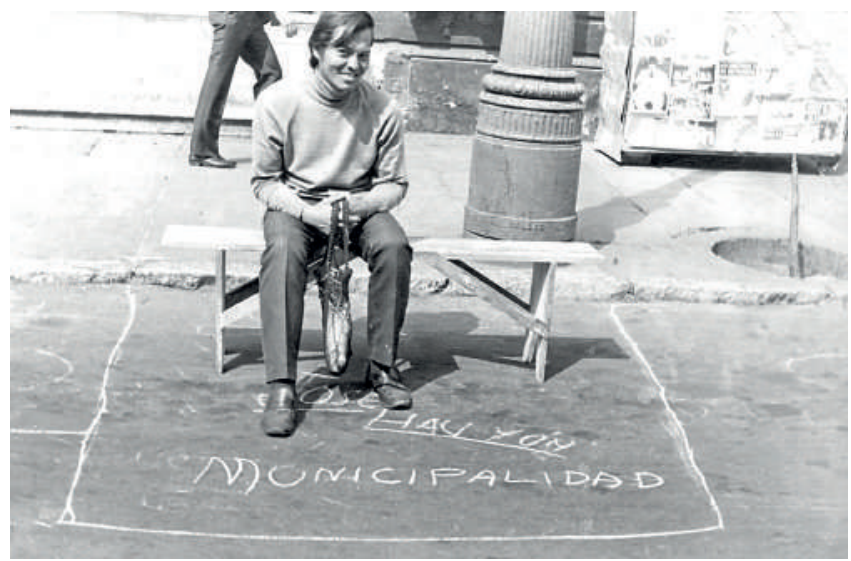

Fig.2. Autor no identificado, s/t, s/f. [Cortesía La República] En el dossier lleva el siguiente pie de foto: "Derechos especiales de dominio. Ambulante lotizando la vía pública” (De Soto, 1986:154).

A simple vista se trata de un conjunto de fotografías que muestran históricamente el mundo popular urbano: desde la llegada en tren a la estación de Desamparados, tras largas horas de viaje hacia la capital; pasando por imágenes de violentos desalojos brutalmente ejercidos por la policía (evidencia de que los autores están del lado del pueblo en su lucha contra el Estado); hasta mostrarnos las formas en que la "creatividad peruana” (fig.2) ${ }^{13}$ se ha hecho camino de forma espontánea ante las torpes barreras estatales ${ }^{14}$. Aparecen también imágenes de combis, mercados populares, viviendas en asentamientos periféricos y talleres de producción. Se trata de fotografías tomadas de los archivos de El Comercio, Caretas y La República, además de capturas de Carlos "Chino" Domínguez, José Casals y Luis Peirano.

El dossier está construido como un montaje donde encontramos una secuencia de imágenes y textos que, a través de las relaciones que establece su estructura narrativa, produce significaciones inéditas sobre el material empleado. Veamos la operación que el texto realiza sobre cada fotografía: en vez de presentar la carretilla (fig.3) como evidencia de una forma precaria del trabajo, donde la mujer debe empujarla esforzadamente a través del arenal, el

10 La edición en inglés del 2002 presenta un extenso prólogo de De Soto orientado a demostrar que su propuesta fue, históricamente, aquella responsable de la derrota de Sendero Luminoso. Desde luego, tras el apoyo a Fujimori por parte del economista en los 90, el prólogo de Vargas Llosa sería eliminado.

11 Recordemos que el escritor lideraba entonces el Movimiento Libertad, que luego formaría parte del FREDEMO para las elecciones presidenciales de 1990.

12 Por razones legales incluyo únicamente las imágenes del dossier cuyas fuentes originales he podido conseguir para su reproducción en este ensayo. En su forma original, sin embargo, éstas aparecen acompañadas por un pie de imagen crucial, que reproduzco a modo de cita textual en las fichas de cada imagen.

13 Véase el pie de foto ampliado en la edición en inglés; "The start of a street market economy. When the street vendors stake out their claim for sales space on a public thoroughfare in Lima, this often signals the birth of a new street market - the natural forum for the working of an informal economy" (De Soto, 2002).

14 No es un dato menor el que aparezca en el dossier el desalojo al Fundo Bocanegra-Garagay de 1985. Este mismo hecho aparece en la segunda serie de la Carpeta Negra (1988) del Taller NN y fue reivindicado por el Movimiento Revolucionario Túpac Amaru -MRTA-, quienes atacaron a la policía en represalia por el desalojo. Al cruzar estos datos queda delineado un campo de lucha ideológica por la articulación política del mundo popular urbano. Sobre la Carpeta Negra, ver Mitrovic (2016). 
pie de foto anuncia que se trata de los "primeros progresos" de una ambulante. La edición en inglés complejiza algo más el comentario:

El segundo paso. El vendedor ambulante [la presenta como masculino] ha invertido los frutos de su trabajo en un medio mejorado para el transporte de sus mercancías, y ahora puede cargar más y con una mayor variedad. El progreso a través del Otro Sendero es más suave y rápido $^{15}$ (De Soto, 2002, traducción propia).

De la misma forma, el peligroso equilibrio del camión-bazar rodante (fig.4) aparece como un índice de progreso en la siguiente imagen: "Ganando economías de escala", lo que permitirá desplazar las mercancías (frazadas) hacia la demanda callejera. El autor del dossier fue el abogado y periodista Enrique Ghersi, quien propuso incluir en el libro un capítulo de fotos. En sus palabras, El Otro Sendero ofreció una "explicación capitalista del desborde popular", donde las imágenes tendrían un papel crucial, no tanto como ilustración del argumento sino como un despliegue de evidencias que sean fácilmente reconocibles por los lectores ${ }^{16}$. El dossier, entonces, resignifica las imágenes que registraron los efectos tempranos del desborde popular en sus usos periodísticos originales.

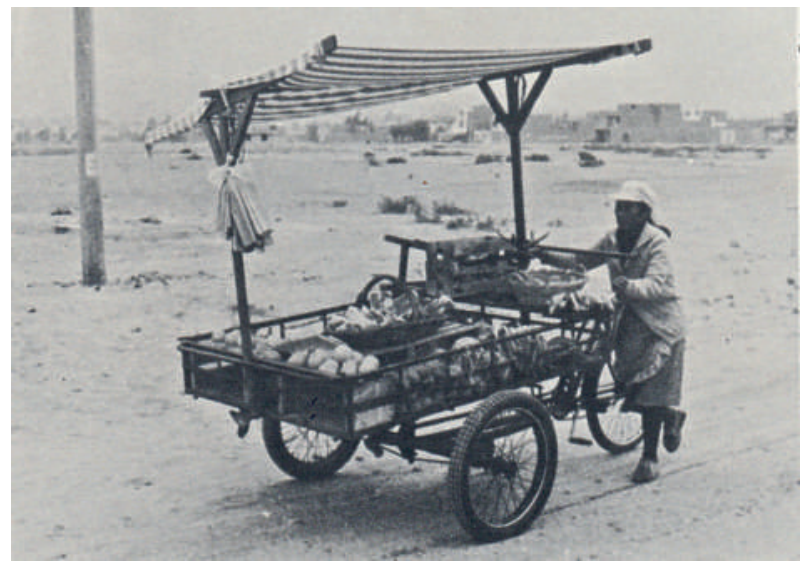

Fig.3. Luis Peirano, s/t, s/f. [Cortesía Luis Peirano] En el dossier lleva el siguiente pie de foto: "Primeros progresos. Ambulante en carretilla" (De Soto, 1986:153).

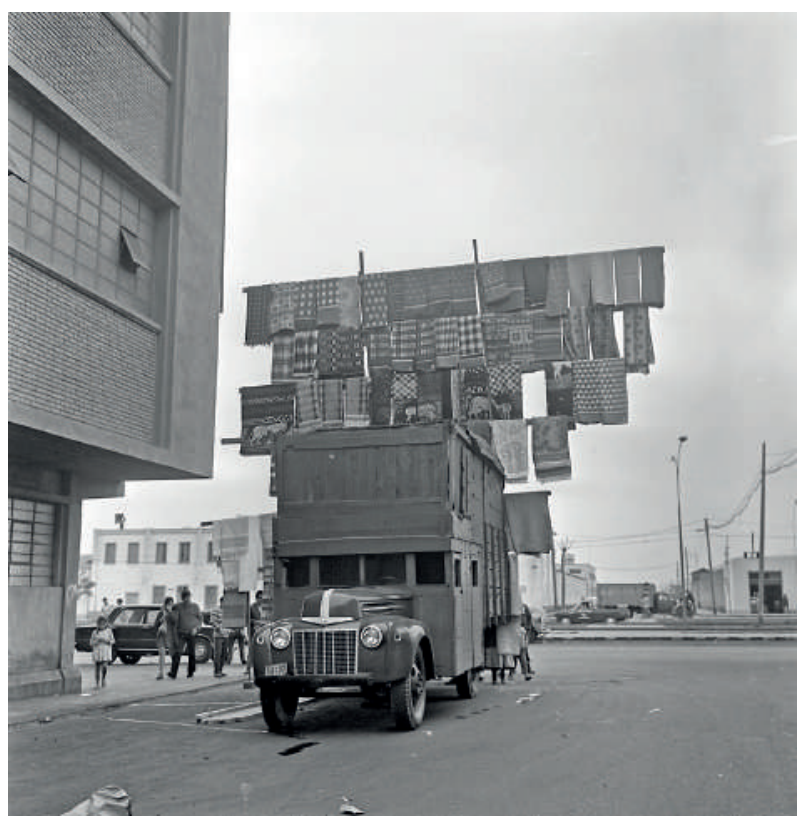

Fig.4. Autor no identificado, Ambulantes. Tomada el 18 de junio de 1971. [Cortesía Revista Caretas] En el dossier lleva el siguiente pie de foto: "Ganando economías de escala. Camión ambulante" (De Soto, 1986:154).

15 Original en inglés: "The second step. The peddler has invested the fruits of his labor in an improved means of transporting his wares. He can now carry more goods with a greater variety. Progress down the Other Path is now smoother and more rapid". Las modificaciones en esta edición son entera responsabilidad de De Soto, pues desde inicios de los 90 Ghersi y Ghibellini se separan del economista ante su apoyo al régimen dictatorial de Fujimori. De Soto autorizó múltiples reproducciones del libro sin consignar a los co-autores, por lo que años más tarde entrarían en un conflicto legal resuelto a favor de Ghersi y Ghibellini.

16 Entrevista con Enrique Ghersi el 04/02/16. 
Pero hay más: presentan a "Poncho Negro”, un famoso organizador de invasiones de los 60 (fig.5); luego conocemos a "Guillotín", dirigente de los ambulantes de la Plaza 2 de Mayo; y a Hernán Chang, líder de la Federación de Choferes del Perú, entre otros personajes. Un panteón de los verdaderos líderes del mundo popular, aquellos que -a diferencia de los políticos- están cerca de las masas, velando genuinamente por sus intereses y necesidades (vivienda, transporte, comercio ambulatorio) ${ }^{17}$.

El proyecto desotiano se formula en términos de una emancipación colectiva contra el Estado, pero una que se basa en la acción individual:

...los distintos peruanos tienen objetivos diferentes $\mathrm{y}$, como es natural, se reservan el derecho a cambiarlos continuamente dentro del rápido proceso de evolución, diversificación e individualización en el que estamos inmersos. Por tanto, no hay necesidad de tratar por enésima vez que el país se ponga de acuerdo en objetivos comunes, porque un "proyecto nacional" que trate de lograr un consenso explícito sobre objetivos precisos es imposible en un país tan heterogéneo y populoso. Antes bien, se trataría de que la institucionalidad legal provea los medios necesarios para que los particulares puedan decidir por sí solos qué objetivos desean perseguir y -a condición de que no perjudiquen a terceroshacer que las leyes les permitan conseguir sus fines (1986:299-300).

Se despliega así un discurso político que tiene puntos de contacto con las vetas culturalistas de la izquierda local, pero alejándose de una concepción colectivista de la emancipación. Las imágenes hasta ahora comentadas aparecen no como representaciones de un sujeto colectivo, sino como epopeyas que deben reenviar únicamente a un imaginario individualista, popular y empresarial ${ }^{18}$. Finalmente, se trataba de “...convertir la lucha de clases en una lucha a favor de un empresariado y una iniciativa populares”19 (Ibídem:312).

17 Pese a la imagen idílica de los líderes mostrados en el dossier, Ghersi comenta que muchos de ellos recibieron un pago por colaborar con las entrevistas y exploraciones etnográficas llevadas adelante por el ILD -práctica común en las ciencias sociales. De esa forma, se pone en evidencia que De Soto no es realmente ese intelectual orgánico que estaría expresando teóricamente los intereses de sus entrevistados, pese a que el libro lo sugiera en múltiples ocasiones.

18 Veamos otra cita:

Es indispensable abandonar de una vez por todas los prejuicios de todo tipo que menosprecian a los informales y hacen creer que, debido a condiciones raciales o culturales, nuestro pueblo es 'distinto' y no está en capacidad de aprovechar las libertades y los sistemas de los países de la economía de mercado [del capitalismo]. Esos prejuicios han servido históricamente para justificar una discriminatoria redistribución de lo poco que tenemos de acuerdo a los criterios de pequeños grupos de interés (De Soto, 1986:311-312).

19 Contra esta lectura que pretende eliminar el carácter de clase de las identidades sociales, la banda Los Shapis propuso identificar a los ambulantes como proletarios en su conocida canción "Ambulante soy". Agradezco a Carlos Adrianzén esta sugerencia. 
Hasta este punto, estamos ante una serie fotográfica que aprovecha la tesis de que las fotografías no comportan, en sí mismas, ningún significado por fuera de su carácter indiciario. Siguiendo la semiótica de Peirce, Rosalind Krauss sostuvo que el índice asumió el papel de modelo operativo del arte contemporáneo a fines de los 70 , pues se hizo cada vez más necesario un suplemento discursivo que signifique la imagen fotográfica, entendida como el registro o documentación del hecho artístico. Así, la "fotografía como evidencia" del arte requería de un comentario escrito que la explique ${ }^{20}$ (Krauss, 1996 [1977]:233). El uso del medio fotográfico por cierto conceptualismo supuso la apertura de un campo de experimentación que articuló imágenes y textos, tanto en sus posibilidades complementarias como en sus fricciones y fracturas. Desde otro ángulo, John Berger hizo énfasis en que las fotografías no son sino huellas físicas del referente -índices- que, privadas de su contexto original -entendido como un ámbito privado donde se sostiene una continuidad entre la captura de la imagen y su significación-, pueden ser empleadas libremente en el ámbito público (2000:49). En ese sentido, el dossier se hizo de imágenes de archivos periodísticos que podían resignificar, practicando -sin el aparato teórico, desde luegouna apropiación de elementos clave del imaginario fotográfico de la ciudad.

Contra las manipulaciones públicas de la imagen fotográfica, Berger sostenía que la práctica crítica debía “...construir un contexto para cada fotografía en concreto, construirlo con palabras, construirlo con otras fotografías, construirlo por su lugar en un texto progresivo compuesto de fotografías e imágenes" (Ibídem: 51). Desde el otro lado del espectro político, el dossier construyó un nuevo contexto para esas imágenes, condensando un ejercicio de apropiación de documentos con la producción de un nuevo marco ideológico que estabilice su sentido.

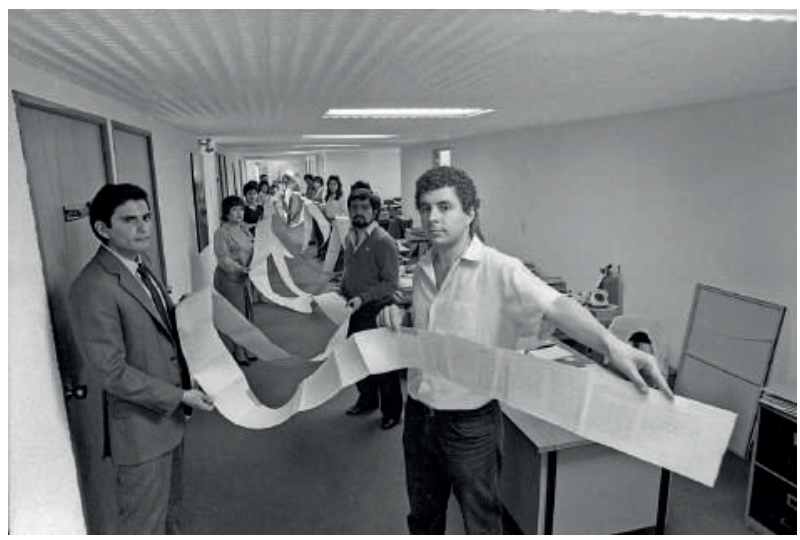

Fig.6. Autor no identificado, Instituto Libertad y Democracia. Tomada el 16 de octubre de 1983. [Cortesía Revista Caretas] En el dossier lleva el siguiente pie de foto: "Simuladores del Instituto Libertad y Democracia (ILD) con una tira de papel de 31 metros de largo: los trámites necesarios para constituir una pequeña industria" (De Soto, 1986:168).

Sin embargo, es en la imagen final del dossier (fig.6) donde aparecen ciertas ideas asociadas con la crítica institucional, un conjunto de prácticas artísticas que apuntan al develamiento de los mecanismos de poder que operan en las instituciones del Estado -entre ellas, y en el contexto europeo-estadounidense, la institución-arte. Para Benjamin Buchloh, la crítica institucional consiste en un desplazamiento donde el arte conceptual abandona las redefiniciones formales de lo artístico para poner en juego ciertas técnicas de recojo de información -como en las obras de Hans Haacke, p.e.- que producen y exhiben datos y dinámicas sociales sobre las instituciones que soportan al arte (2004:197-198). Siguiendo a Hito Steyerl (2006), lo anterior corresponde a la "primera ola" de crítica institucional, orientada a la democratización de la institución-arte, vista como parte integral de los aparatos del Estado. En los 90 esa identificación se complicará ante la privatización de las instituciones públicas por parte de las reformas neoliberales en todo el mundo, y las prácticas artísticas

20 Para una genealogía de la relación entre fotoperiodismo y fotoconceptualismo, ver Jeff Wall (2003). Puede ser provechosa la lectura del autor de la obra Homes for America (1965) de Dan Graham. 
transitarán desde una crítica de la institución hacia una crítica de la representación -apuntando a la inclusión de las minorías sociales al interior de los espacios culturales, ahora privatizados. Así, la crítica artística se concentra actualmente en producir reivindicaciones simbólicas ante la progresiva desaparición de un aparato institucional de carácter público.

De forma más general, Simon Sheikh sugiere que la noción de crítica institucional enlaza un método -la crítica- y un objeto -las instituciones- (2009:29). Así, podemos entender la imagen de la simulación de los trámites necesarios para constituir una pequeña empresa como una operación de crítica institucional neoliberal que, sin intenciones artísticas, presenta un objeto - una tira de 31 metros de largo- como evidencia indiscutible del gigantismo del Estado, revelándolo como un ente que traba el progreso popular. Un rollo interminable de trámites burocráticos kafkianos que conduce al lector a la indignación $\mathrm{y}$, finalmente, a tomar posición contra el enemigo ${ }^{21}$. El objeto de la crítica queda claro, pero el método es más complejo: en el cuerpo del texto se comentan los pormenores de la simulación llevada adelante por el ILD en 1983, quienes montaron “...un pequeño taller de confecciones de prendas de vestir en una zona industrial de la Carretera Central en el distrito de Ate, en las afueras de Lima, y [decidieron] tramitar ventanilla por ventanilla su constitución regular" (De Soto, 1986:173). Para poder comprender los costos de la informalidad, alquilaron el local de una fábrica y contrataron a cuatro personas para que llevaran adelante los trámites, bajo supervisión de un abogado. El rubro elegido -la pequeña industria textil-, permitió conseguir una muestra "altamente representativa" de "los trámites comunes a todas las actividades industriales", así como de los trámites de las personas naturales (Ibídem:174).

Se establecieron ciertas reglas de operación: no se pagarían coimas salvo cuando aquella fuese la única posibilidad para conseguir la constitución legal de la empresa, viéndose obligados a acceder al soborno en dos oportunidades y rechazando ocho invitaciones al atajo legal. Simularon también el lugar de vivienda de los empresarios -Villa El Salvador-, añadiendo el tiempo de desplazamiento hasta los centros administrativos oficiales. ¿Cuál fue el resultado final?: “...que una persona modesta debía tramitar durante 289 días antes de obtener los once requisitos previos a la instalación de una pequeña industria" (Ibídem:174). Calcularon también la pérdida de utilidades netas de la empresa en los diez meses empleados en el trámite, añadiéndole los costos oficiales de la operación. En esa época, el costo final del proceso era de 1231 dólares americanos, 32 veces el sueldo mínimo vital del país. Además de desplegar los datos y conclusiones, confirmaron la incapacidad del Estado a todo nivel, pues nadie advirtió que se trataba de una simulación ${ }^{22}$.

La tira de papel y la simulación pretenden mostrar los efectos del Estado mercantilista, y lo hacen como experimentos visuales y conceptuales que evidencian la necesidad de reducir los trámites legales para la formalización, de asumir que “...el progreso no resulta exclusivamente de la acción del Estado”, sino que el que produce es el pueblo (Ibídem:290-291). Desde ese marco, el problema del Estado es que no ha logrado ser realmente moderno: sus leyes, según De Soto, pretenden “...gobernar cada cosa, cada transacción, cada propiedad” y deben ser sustituidas por “....instituciones legales eficientes que incentiven los fines

21 En la edición en inglés la imagen lleva una nota final, que dice: "The logic of informality on the Other Path is clearly demonstrated" (De Soto, 2002). Se muestra entonces la intención demostrativa que anima la inclusión de esta imagen.

22 En su proyecto documental The Heavens (2015), el fotógrafo Paolo Woods y el escritor Gabriele Galimberti recorrieron por dos años múltiples paraísos fiscales a nivel global, complejizando la imagen recurrente que los presenta como playas tropicales rodeadas de palmeras. Para la publicación del libro The Heavens: Annual Report -aprovechando la forma usual de los informes de actividades que las empresas exitosas imprimen-, los autores crearon una empresa en Delaware, uno de los estados de los Estados Unidos donde los trámites de constitución empresarial son prácticamente nulos. Ver: http://www.theheavensllc.com/ 
deseados [por los individuos]" (Ibídem:291). Finalmente, el dossier presenta una historia lineal de la informalidad, pero concluye demostrando que es la formalidad la que imposibilita el feliz desenlace del relato.

\section{El porvenir de una ideología}

La crítica institucional es una parte constitutiva de la burguesía tal como fue pensada por Karl Marx y Friedrich Engels en El Manifiesto Comunista de 1848, pues se caracteriza por su "capacidad para abolir y disolver las instituciones caducas, todo aquello que es inútil y está petrificado, mientras que la forma general de la autoridad, en sí misma, no se ve amenazada" (Steyerl, 2006). La burguesía hizo su entrada en la historia como una clase dispuesta a disolver la llamada "sociedad tradicional", cuyos rezagos aparecen en El Otro Sendero en el carácter mercantilista del Estado peruano -un aparato de privilegios antes que uno que establezca derechos realmente abstractos y universales. La diferencia entre este sentido ampliado de crítica institucional y sus definiciones circunscritas a la práctica artística consiste en que las segundas, al ser examinadas históricamente, aluden al proceso mediante el cual la crítica se desplazó desde las instituciones -museos, galerías, etc.- hacia la propia subjetividad artística ${ }^{23}$. Desde la esfera de la circulación hacia la producción misma del arte, pero entendiendo esta última como un espacio subjetivo e infinitamente (auto)reflexivo, en vez de insistir en la crítica de las instituciones sociales que lo soportan -lo que implicaría también aceptar plenamente la constitución social de toda subjetividad artística (Sheikh, 2009:31-32).

Para comprender el tipo de crítica institucional operada por El Otro Sendero es necesario dejar de asociar la categoría únicamente con una política de izquierdas. El caso analizado plantea desafíos a la historiografía del arte contemporáneo en el Perú, pues sugiere que ciertas operaciones no-artísticas (como múltiples otras que se incorporan constantemente a los relatos del arte local) comparten intenciones críticas y lógicas de acción que han sido pensadas desde las teorías del arte contemporáneo a nivel global, pero que se diferencian de las ideologías implicadas en ellas. Y es que buena parte del discurso del arte contemporáneo sostiene una relación natural y generalizada entre lo artístico y lo progresistademocrático, amparada en el incuestionable "sentido emancipatorio" del arte entendido como pluralización de la experiencia sensible (Malik, 2015).

A nivel local, la crítica institucional neoliberal llama la atención sobre el carácter políticamente ambiguo de la insistencia en que el responsable histórico de las inconsistencias de nuestro campo artístico es el Estado, pues se deja de analizar cómo la institución del mercado capitalista recientemente ha llenado el "vacío" institucional denunciado por artistas y curadores locales ${ }^{24}$. Acaso sin buscarlo, aquel discurso se encuentra sin problemas con la ideología anti-estatal neoliberal al culpabilizar al Estado y asumir una suerte de necesidad histórica de un sistema artístico privado. Ante ello, hace falta analizar las relaciones sociales concretas -las personas y los grupos, los lobbies, los intereses, los discursos, los usos de las plataformas públicas existentes, etc.- que enlazan al mercado del arte y al Estado, en vez de sostener su oposición abstracta. La estrategia crítica de "entrar y salir" de la institución (propugnada por múltiples artistas) requiere de un esfuerzo por especificar de qué institución se está hablando: si se trata de las instituciones del Estado, ¿modifica en algo la fórmula el que, a nivel local, buena parte de las instituciones "oficiales" sean privadas? ${ }^{25}$

23 Una forma terminal de este proceso puede ser leída en el artículo del 2011 "L'1\%, C'EST MOI” de la artista estadounidense Andrea Fraser (2016: 26-36).

24 "Vacío museal" diría Gustavo Buntinx (s.f) en una conocida categoría entre curadores y artistas locales. Habría que discutir la dinámica capitalista en el arte limeño reciente analizando de forma concreta si el vacío institucional aún describe a la escena local.

25 No estamos hablando de servicios públicos "privatizados", sino que éstas fueron engendradas siempre ya como instituciones privadas en el Perú. 
Hace falta pensar el soporte institucional del arte, para luego discutir las estrategias de una crítica institucional que no continúe arguyendo que el arte contemporáneo es, en sí mismo y de forma incuestionable, un espacio utópico que siempre será potencialmente más radical y efectivo que lo que actualmente es. Frente a ello, habría que reclamar la necesidad no solo de la crítica -artística o no-, sino de pensar la relación entre el arte y la ideología como un campo de praxis política afirmativa ${ }^{26}$.

Dijo Alberto Flores Galindo que "el porvenir de una ideología es muy pobre si sólo se convierte en un libro. Las ideas de Hernando De Soto aspiran a llegar más lejos, hasta confundirse con el sentido común" (1996 [1988]:187). Como temprana expresión teórica del neoliberalismo local, El Otro Sendero encontró su desarrollo histórico en el discurso emprendedor que estructura actualmente al sujeto popular. En este contexto, ¿no será que las subjetividades artísticas locales responden también a estas coordenadas ideológicas?

\section{Referencias}

Adrianzén, C. (2010). De Soto y la (im)posible apuesta por un neoliberalismo popular. En: G. Portocarrero, J. Ubillúz \& V. Vich, Cultura política en el Perú. Tradición autoritaria y democratización anómica (pp. 95-108). Lima: Red para el Desarrollo de las Ciencias Sociales en el Perú.

Adrianzén, C. (2014a). El Mesías de las élites. Revista Poder. Recuperado de: https:// revistapoder.lamula.pe/2014/07/31/el-mesias-delas-elites/poder/ [Consulta: 2 Jul. 2016].

Adrianzén, C. (2014b). Una obra para varios elencos. Apuntes sobre la estabilidad del neoliberalismo en el Perú. Nueva Sociedad, 254 (noviembre-diciembre), 100-111.

Berger, J. (2000). Usos de la fotografía. Elementos, 37, 47-51.

Buchloh, B. (2016). El arte conceptual de 1962 a 1969: de la estética de la administración a la crítica de las instituciones. En: B. Buchloh, Formalismo e historicidad. Modelos y métodos en el arte del siglo XX (pp. 166-199). Madrid: Akal.

Buntinx, G. (s.f.) Vacío museal. Micromuseo.org. pe. Recuperado de: http://micromuseo.org.pe/ rutas/vacio-museal/sinopsis.html [Consulta: 20 de julio 2016].

Camnitzer, L. (2009). Didáctica de la liberación. Arte conceptualista latinoamericano. Murcia: CENDEAC.

De Soto, H. (2002). The Other Path. The Economic Answer To Terrorism. New York: Basic Books.
De Soto, H. (en colaboración con Ghersi, E., Ghibellini, M. \& Instituto Libertad y Democracia) (1986). El Otro Sendero. La Revolución Informal. Lima: El Barranco.

Degregori, C., Blondet, C., \& Lynch, N. (1986). Conquistadores de un nuevo mundo. De invasores a ciudadanos en San Martín de Porres. Lima: Instituto de Estudios Peruanos.

Durand, F. (2007). El Perú fracturado. Formalidad, informalidad y economía delictiva. Lima: Fondo Editorial del Congreso del Perú.

Flores Galindo, A. (1996 [1988]). Los caballos de los conquistadores, otra vez. (El otro sendero). En: Obras Completas. Tomo IV (pp. 171-185).

Lima: CONCYTEC, SUR - Casa de Estudios del Socialismo.

Fraser, A. (2016). De la crítica institucional a la institución de la crítica. México D.F: Siglo XXI.

Ghersi, E. (2004). El mito del neoliberalismo. Estudios Públicos, 95, 293-313.

Gonzáles, O. (2011). La izquierda peruana: Una estructura ausente. En: A. Adrianzén, Apogeo y crisis de la izquierda peruana. Hablan sus protagonistas (pp. 15-43). Lima: Instituto Internacional para la Democracia y la Asistencia Electoral (IDEA Internacional), Universidad Antonio Ruiz de Montoya

Harvey, D. (2007). Breve historia del neoliberalismo. Madrid: Akal.

26 En ese sentido, la autocrítica de Ghersi resulta ejemplar para la izquierda: "Muchas veces creemos que para triunfar en la lucha por la libertad basta con la abrumadora evidencia de los hechos. No obstante, ellos son insuficientes para causar la convicción necesaria en el debate ideológico" (2004:312). 
Krauss, R. (1996). Notas sobre el índice. En: R. Krauss, La originalidad de la vanguardia y otros mitos modernos (pp. 209-235). Madrid: Alianza Editorial.

López, S. (2009). La reinvención de la historia desde abajo. Libros y Artes: Revista de Cultura de La Biblioteca Nacional del Perú, 30-31.

Malik, S. (2015). Reason to destroy contemporary art. En: C. Cox, J. Jaskey \& S. Malik, Realism, Materialism, Art (pp. 185-191). Nueva York, Berlin: CCS Bard, Sternberg Press.

Matos Mar, J. (1984). Desborde popular y crisis del Estado. El nuevo rostro del Perú en la década de 1980. Lima: Instituto de Estudios Peruanos.

Martuccelli, D. (2015). Lima y sus arenas. Poderes sociales y jerarquías culturales. Lima: Cauces Editores.

Mitrovic, M. (2016). Organizar el fracaso. Arte y política en la Carpeta Negra. Lima: Garúa ediciones.
Rochabrún, G. (2007). Del mito proletario al mito popular. (Notas para el caso peruano). En: G. Rochabrún, Batallas por la teoría: en torno a Marx y el Perú (pp. 293-310). Lima: Instituto de Estudios Peruanos.

Sheikh, S. (2009). Notes on Institutional critique. En: G. Raunig \& G. Ray, Art and Contemporary Critical Practice. Reinventing Institutional Critique (pp. 29-32). Londres: Mayfly.

Steyerl, H. (2006). La institución de la crítica. Transversal, 01. Recuperado de: http://eipcp.net/ transversal/0106/steyerl/es

Wall, J. (2003). 'Señales de indiferencia': aspectos de la fotografía en el arte conceptual o como arte conceptual. En: G. Picazo \& J. Ribalta, Indiferencia y Singularidad: la fotografía en el pensamiento artístico contemporáneo (pp. 213-249). Barcelona: Gustavo Gili.

Recibido el 6 de setiembre de 2016. Aceptado el 12 de octubre de 2016. 